\title{
Consumer intention to purchase green vehicles in the South African market: A theory of planned behaviour perspective
}

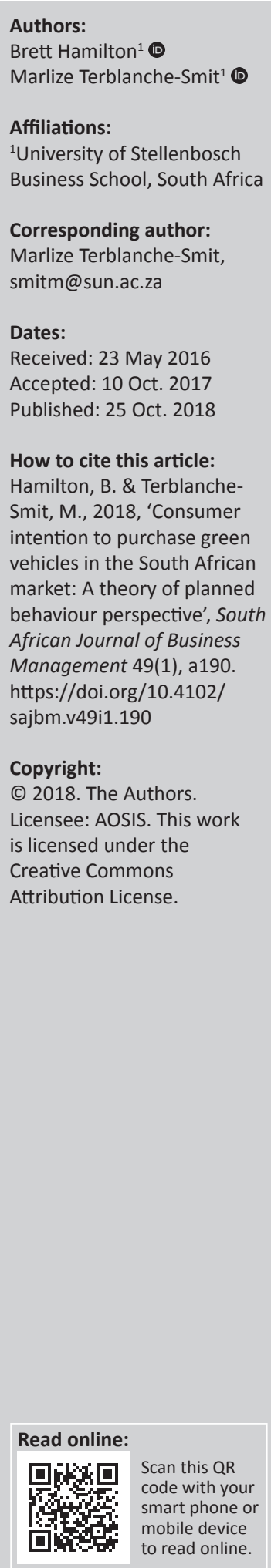

Background: While alternative fuel vehicles (AFVs) still account for a relatively small percentage of the total vehicle sales, this is set to change as awareness of the impact of car usage on the environment grows among consumers, vehicle-emission controls increase and the number of AFVs available in the market increases.

Objective: This study used Ajzen's theory of planned behaviour (TPB) to investigate the role of attitude (A), subjective norm (SN) and perceived behavioural control (PBC) on the intention to purchase AFVs in the South African market and thus empirically testing the hierarchical attitude-behaviour model of consumer behaviour.

Method: A quantitative research methodology was followed and a self-administered, Internetbased survey instrument was used to collect data from 196 South African respondents.

Results: The findings indicate significant relationships between $\mathrm{A}(\beta=0.61), \mathrm{SN}(\beta=0.26)$, and $\operatorname{PBC}(\beta=0.13)$ and behavioural intention. These findings support literature and emphasise that (1) attitudinal factors have the biggest influence on intention, (2) the perceived support and encouragement of referent others are important considerations for individuals and (3) control factors play a critical role in consumers' decision to purchase an AFV.

Conclusion: In order to create effective marketing strategies for AFVs retailers and marketers should focus on the impact of attitude, subjective norm (SN) and perceived behavioural control (PBC) to influence behavioural intention.

\section{Introduction}

Concerns regarding pollution, depleting fossil fuel reserves and climate change mean that consumers have become aware of the effect of their behaviour on the environment (Jansson, Marell \& Nordlund 2011), and this has given rise to 'green consumerism' (Follows \& Jobber 2000). In addition, many companies are adopting green marketing strategies and environmental product attributes as a form of competitive advantage (Akehurst, Afonso \& Gonçalves 2012).

In the automotive industry, alternative fuel vehicles (AFVs) have been introduced as a green alternative that is less harmful to the environment. AFVs make use of a conventional petroleum or diesel internal combustion engine (ICE) in addition to at least one other type of propulsion system, including electric-drive vehicles (EVs), bio-fuels, fuel-cells, compressed natural gas, etc. (Egbue \& Long 2012). For purposes of this study, AFVs refer to hybrid EV that uses an ICE along with an electric motor for propulsion and EV that partly or in its entirety uses electricity for its propulsion, as these are the only type of AFVs currently available in the South African market (Egbue \& Long 2012). Offering green products that are less harmful for the environment, such as AFVs, has many potential benefits as it does not only meet the needs of environmentally concerned consumers but also positively impacts on the brand image, reputation and financial performance of a company. It may also contribute to a sustainable solution to environmental, economic and energy concerns (Chen \& Chai 2010; Egbue \& Long 2012). However, despite a significant rise in green awareness among consumers, merely offering green products does not guarantee long-term market success for companies (Hansen, Risborg \& Steen 2012).

This is evidenced by findings that despite consumers stating to have positive attitudes towards green products and green behaviour, there remains a gap between positive attitudes and actual market data. This is referred to as the attitude-action gap, as highlighted by Belk (1985). For example, only $0.48 \%$ of new vehicles registered in 2013 in Belgium were AFVs (ADSEI 2014); lowcarbon cars (those emitting less than $100 \mathrm{~g}$ of $\mathrm{CO}_{2}$ per $\mathrm{km}$ ) represented only $0.1 \%$ of UK car sales 
(Lane \& Potter 2007) and only $0.12 \%$ of new vehicles sold in South Africa during 2013 were AFVs (0.17\% during 2012) (Lightstone Auto 2014). In many cases, these low figures are in spite of government incentives for the purchase or use of green vehicles, government disincentives for the use of conventional vehicles (CVs) and the availability of numerous AFVs in the market (Egbue \& Long 2012; Lane \& Potter 2007).

While technological (such as battery technology limitations and high costs) and situational factors (such as economic and regulatory factors) do curtail the adoption of AFVs (Egbue \& Long 2012), a study by Darnton (2004) on behalf of the British Department of Environment, Food and Rural Affairs found major barriers to their wider adoption based on attitudinal factors. Consequently, understanding green consumer behaviour is important because, as more AFVs become available, consumers have greater opportunities to express their environmental values and attitudes (Jansson et al. 2011). It is therefore important for companies and marketers to understand what influences green consumer behaviour and utilise this to develop effective green marketing strategies (D'Souza, Taghian \& Khosla 2007; Hansen 2008; Kim \& Chung 2011).

Developing such strategies relies heavily on the level of understanding of consumer behaviour and specifically, on positive consumer attitudes that are antecedent to purchase behaviour. It is thus important to understand consumer attitudes towards green products. However, as evidenced by the attitude-action gap, this is not always sufficient. According to Schiffman and Kanuk (2007), while attitudes are consistent with behaviour, they are not permanent and may change over time and under different situations. This, thus, calls for a deeper understanding of the determinants of green consumer behaviour with which effective marketing strategies can be developed.

The theory of planned behaviour (TPB), which was developed by Ajzen (1985), sees attitudes as antecedent to intention and purchase behaviour. This research was designed to examine the purchase intention of South African consumers with regard to AFVs based on the TPB. It further considered subjective norm (SN) and perceived behavioural control (PBC) as predictors of purchase intention and, additionally, the moderating influence of $\mathrm{PBC}$ on the relationship between attitude and intention to better explain the attitude-action gap. It focused on AFVs, more specifically on hybrid and electric-drive vehicles (HEVs and EVs), as these were the only types of AFVs available in the South African market during the study.

This research should serve as a guide for companies and marketing managers who intend to market AFVs in South Africa, to gain an in-depth understanding of consumer purchase intention and to develop effective green marketing strategies for AFVs.

\section{The theory of planned behaviour}

The TPB is a reasoned action framework developed by Ajzen (1985) in order to define, predict and change consumer behaviour.
According to the TPB, actual behaviour is determined by the intention to perform behaviour (behavioural intention, BI), while this intention is jointly influenced by an individual's attitude towards performing behaviour (A), perceived social influence of referent others (subjective norm, $\mathrm{SN}$ ) and $\mathrm{PBC}$ over performing behaviour. These three determinants of intention, in turn, follow from an individual's beliefs (Ajzen 2012; Kim \& Chung 2011).

The TPB is widely used and has been applied in a variety of contexts (Moons \& De Pelsmacker 2012), including behaviour related to the environment (e.g. Hansen et al. 2012; Kim \& Chung 2011; Ramayah, Lee \& Mohamad 2010).

\section{Theoretical framework and research hypotheses}

The theoretical framework of this study comprises four hypotheses and is shown in Figure 1. The framework proposes the link between the following variables: attitude, SN, perceived behaviour control and behavioural intention.

\section{Attitude and behaviour}

An attitude can be defined as an enduring favourable or unfavourable evaluation or feeling a consumer has over or towards a product, behaviour, service, object or event (Kotler \& Keller 2012). An individual is more likely to perform specific behaviour if he or she has a positive attitude towards performing behaviour. Numerous studies support this positive relationship, including those related to purchasing environmentally responsible products or performing environmentally friendly behaviours (Chan \& Lau 2001; Kalafatis et al. 1999; Soyez 2012), the purchase of organic personal care products in the United States $(\beta=0.39, p<0.001)$ (Kim \& Chung 2011), electric-car buyers in Belgium $(\beta=0.263$, $p<0.001$ ) (Moons \& De Pelsmacker 2012) and the purchase of green electricity ( $\beta=0.36, p<0.001$ ) (Hansla et al. 2008). This study proposes the following hypothesis:

H1: Attitude towards purchasing AFVs is positively related to intention to purchase AFVs (BI).

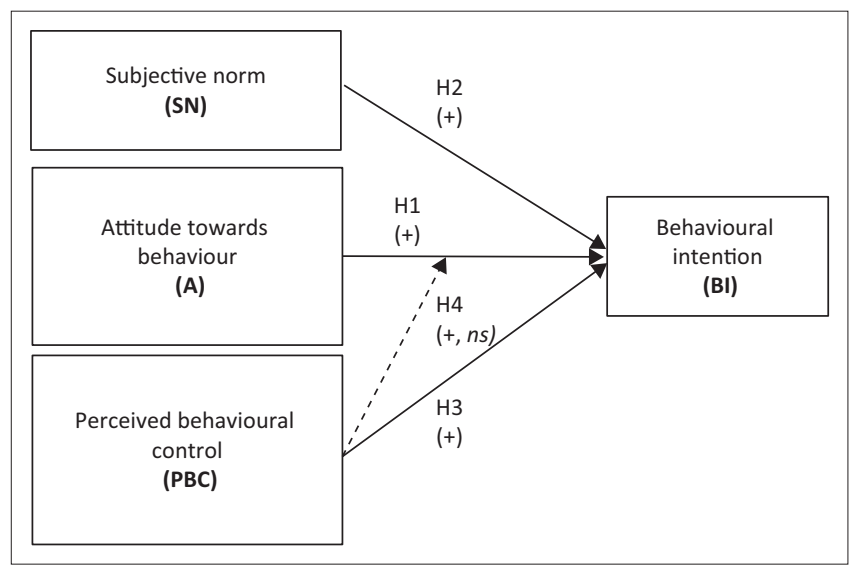

Source: Adapted from Hansen et al. 2012:479 and Kim \& Chung 2011:41

FIGURE 1: Relationship between constructs. 


\section{Subjective norm and behaviour}

A SN consists of the normative belief that a referent other wants an individual to perform behaviour or not and that this belief is moderated by an individual's motivation to comply with that referent (Kim \& Chung 2011). An individual may have more than one referent other, and it might also be a group known as a reference group (Kotler \& Keller 2012). The correlation between $\mathrm{SN}$ and behavioural intention has been shown in research on green consumer behaviour (e.g. Bamberg 2003; Kalafatis et al. 1999). A cross-cultural study on pro-environmental values and behaviour conducted by Soyez (2012) found varying, but positive, correlations between SN and behavioural intention. Specific studies related to the purchase intention of organic personal care products (Kim \& Chung 2011) and free-of cosmetics (Hansen et al. 2012) also found positive correlations. This study proposes the following hypothesis:

$\mathrm{H} 2$ : Subjective norm related to AFVs (SN) is positively related towards intention to purchase AFVs (BI).

\section{Perceived behavioural control and behaviour}

Despite consumers having both positive attitudes towards and there being positive social pressure to perform a certain behaviour, it may still be difficult for them to perform (Ajzen 2005). It is expected that the level of actual control that an individual has over behaviour will moderate behavioural intention (Ajzen 2012). For example, when an individual has an intention to perform behaviour and also has a high level of control over behaviour, it is likely that the individual will perform behaviour. Perhaps as important as actual control is the $\mathrm{PBC}$ that an individual has over performing behaviour. This is the belief that an individual has that he or she will be able to perform behaviour if he or she chooses to do so (Chen 2007). Empirical research supports the link between PBC and behavioural intention in the environmental domain. The study by Kim and Chung (2011) into the purchase intention of organic personal care products found a correlation of 0.31 $(p<0.001)$, and the cross-cultural study by Soyez (2012) also found positive relationships (USA: 0.26; Canada: 0.23; Australia: 0.27; Germany: 0.25 and the Russian Federation: 0.43; all $p<0.001$ ). The study by Hansla et al. (2008) found that costs related to green electricity had a moderating effect on willingness to purchase (2008). This study proposes the following hypothesis:

H3: Perceived behavioural control related to AFVs (PBC) is positively related towards intention to purchase AFVs (BI).

\section{Perceived behavioural control as moderator}

An interesting addition to the TPB was done by Kim and Chung (2011) in their study of consumer purchase intention for organic personal care products. The authors were curious to the fact that numerous studies have found that despite a consumer having a positive attitude towards behaviour, the consumer may not develop an intention to perform behaviour when he perceives difficulties to do so (Chen 2007). Their study found that the attitude-intention relationship is indeed moderated by PBC. This goes some way in explaining the socalled attitude-action gap. This study proposes the following hypothesis:

$\mathrm{H} 4$ : The greater the $\mathrm{PBC}$ is, the stronger the positive relationship between attitude towards purchasing AFVs (A) and intention to purchase AFVs (BI).

\section{Methodology Data collection}

The data of this study were collected from a self-administered, Internet-based survey of South African consumers. The survey questionnaire was distributed to a database of e-mail addresses that was conveniently available, consisting of weekly web letter subscribers of CAR magazine, South Africa's biggest selling automotive magazine (RamsayMedia 2014). Of the 201 responses, 196 were deemed suitable for use in the study.

Compared with the statistics on the South African population, with a male population of $48.2 \%$, males, highly educated and affluent individuals were overrepresented in the data (RamsayMedia, 2014). Given the demographic statistics ofCARmagazinereaders, theseoverrepresentations were expected. Of the responses, $95.41 \%$ were male and $4.59 \%$ female. Most respondents $(21.94 \%)$ were between 25 and 29 years, with $51.53 \%$ of the respondents being less than 35 years of age. The respondents were highly educated, with $82.14 \%$ having attained a qualification beyond matric or grade 12 . Of the respondents, $61.73 \%$ indicated a monthly household income of more than R25 000. The group with the highest representation $(20.41 \%)$ had a monthly household income between R30 000 and R39 999. Half of the respondents indicated that their monthly household income was more than R30 000, indicating an affluent sample.

\section{Measurement}

Multiple-item scales were constructed for all the variables in this study. The survey questionnaire included questions based on attitude, SN, PBC and behavioural intention. Questions based on demographic and sociodemographic data were also included.

\section{Measuring attitude}

Attitude was measured on the basis of the agreement of respondents to four statements, as derived from Soyez (2012) and Hansen (2008). A5-point Likert scale was used (1 = strongly disagree; 5 = strongly agree) .

\section{Measuring subjective norm}

Subjective norm was measured on the basis of the agreement of respondents to five statements, as derived from the literature review (Hansen 2008; Hansen et al. 2012; Kim \& Chung 2011; Moons \& De Pelsmacker 2012; Soyez 2012). A 5-point Likert scale was used ( $1=$ strongly disagree; $5=$ strongly agree). 
TABLE 1: Results of the multiple regression model. Multiple regression analysis: Predicting intention to purchase AFVs

\begin{tabular}{llcccl}
\hline Hypothesis & Path & $\boldsymbol{\beta}$ & $\boldsymbol{t}$ & $\boldsymbol{p}$ & Test result \\
\hline H1 & A-BI & 0.61 & 11.62 & 0.00 & Fail to reject \\
H2 & SN-BI & 0.26 & 4.95 & 0.00 & Fail to reject \\
H3 & PBC-BI & 0.13 & 3.27 & 0.00 & Fail to reject \\
H4 & AxPBC & 0.00 & - & 0.73 & Rejected \\
- & Change $R^{2}$ & 0.11 & - & - & - \\
- & Change $F$ & - & - & - & - \\
\hline
\end{tabular}

A, attitude; SN, subjective norm; PBC, perceived behavioural control; BI, behavioural intention AFVs, alternative fuel vehicles; $\beta$, Beta-coefficient; $t, \mathrm{t}$-value; $p$ : $\mathrm{p}$-value

Note: Overall results: $R^{2}=0.71, F(3.192)=158.58, p<0.00$

\section{Measuring perceived behavioural control}

Perceived behavioural control was measured by way of the agreement of respondents to five statements, as derived from the literature review (Hansen 2008; Kim \& Chung 2011; Moons \& De Pelsmacker 2012). A 5-point Likert scale was used $(1=$ strongly disagree; $5=$ strongly agree $)$.

\section{Measuring behavioural intention}

Marketers are primarily interested in a consumer's behavioural intent and will thus be interested in asking respondents about their likelihood to behave in a certain manner or their intention to behave in a certain manner (Zikmund \& Babin 2010). Behavioural intention was measured by way of the agreement of respondents to four statements, as derived from the literature review (Hansen et al. 2012; Kim \& Chung 2011; Moons \& De Pelsmacker 2012; Ramayah et al. 2010). A 5-point Likert scale was used $(1=$ strongly disagree; $5=$ strongly agree).

\section{Ethical considerations}

Ethical approval was received for the manuscript. Ethical clearance was not required at the time the study was conducted, as all respondents were informed that their participation was anonymous. All the ethical considerations of the University of Stellenbosch were adhered to.

\section{Results}

\section{Reliability results for the variables}

This study made use of summed scales in order to measure the constructs of attitude, SN, PBC and behavioural intention. There were no missing data from the data set, and the internal reliability of the summed scales was measured with Cronbach Alpha coefficients. All summed scales used in this study in order to measure attitude, SN, PBC and behavioural intention were found to be internally reliable with Cronbach Alpha coefficients of $0.89,0.89,0.84$ and 0.93 , respectively, which are above the generally accepted lower limit of 0.7 (Peterson 1994).

\section{Testing of the hypotheses}

To test the hypotheses of this study, a multiple regression was performed. The regression model measured the correlation relationship between behavioural intention to purchase AFVs and attitude, $\mathrm{SN}$ and $\mathrm{PBC}(\mathrm{H} 1-\mathrm{H} 4)$. The result of the second regression model, including the beta-coefficients, standard error, $t$-values and significance, is shown in Table 1.
As expected, the overall regression equation of the regression model was found to be significant $\left(R^{2}=0.71, F(3.192)=158.58\right.$, $p<0.01)$. The significance of the partial regression coefficients could be found, and $\mathrm{H} 1-\mathrm{H} 4$ could be supported. It was proposed that attitude towards purchasing AFVs was positively related to intention to purchase AFVs (H1): This proposition was supported $(\beta=0.61, \mathrm{t}(192)=11.62, p<0.01)$. It was proposed that $\mathrm{SN}$ was positively related to intention to purchase AFVs (H2): This proposition was supported $(\beta=0.26$, $\mathrm{t}(192)=4.95, p<0.01)$. It was proposed that PBC was positively related to intention to purchase AFVs (H3): This proposition was supported $(\beta=0.13, \mathrm{t}(192)=3.27, p<0.01)$.

This study also attempted to determine if the relationship between attitude and intention is moderated by PBC (H4). Different from the finding of Kim and Chung (2011), this moderating effect was not supported, and the research did not identify a significant change in the variance of intention once the interaction terms were added $\left(R_{\text {change }}^{2}=0.00, F_{\text {change }}=\right.$ $0.11, p=0.74)$. Thus, hypothesis four was not supported in this study.

\section{Discussion}

This study attempted to identify those factors that underlie consumer behaviour. It considered attitude, SN and PBC as predictors of purchase intention and, additionally, the moderating influence of PBC on the attitude-action gap.

The research found a significant positive relationship between attitude and behavioural intention, and H1 was supported. This confirms that consumers with more positive attitude towards AFVs will exhibit a greater intention to purchase an AFV. Of the three constructs measured in the regression model, attitude was the most significant determinant of behaviour; as such, creating a positive attitude towards AFVs must be a significant consideration for developing an effective marketing strategy for AFVs.

The research found a significant positive relationship between $\mathrm{SN}$ and behavioural intention to purchase AFVs; $\mathrm{H} 2$ was therefore supported. This confirms that consumers are not only influenced by their attitude towards AFVs but also by their social surroundings, and consumers who perceive greater social pressure to purchase AFVs will exhibit a greater intention to do so. In general, respondents felt a positive social norm towards purchasing AFVs. The significance of $\mathrm{SN}$ in predicting the intention to purchase an AFV is because of at least two factors: As highlighted by Hansen et al. (2012), environmental behaviour is often a new behaviour for consumers. This is certainly the case with AFVs and often means that consumers lack (or feel to lack) the knowledge required to make an informed decision. Thus, they rely on the support and guidance of friends, family or opinion leaders to guide their behaviour. They may also rely on the media that would have had experience with AFVs. As driving and owning a vehicle is a highly visible behaviour, the image associated with the behaviour is often also a significant determinant. This may also influence the need of a consumer 
to comply with social norms or to conduct what they perceive to be is the right behaviour. From the point of view of developing effective marketing strategies for AFVs, marketers may want to focus on creating normative pressure and improving the knowledge of consumers regarding AFVs.

The research found a significant positive relationship between PBC and behavioural intention, and $\mathrm{H} 3$ was supported. This confirms that control factors' (either adding difficulty or ease to behaviour) impact on behaviour. In general, respondents feel control factors inhibit their ability to purchase an AFV. These could include purchase price, having access to charging facilities and the ease of using an AFV over a conventional vehicle. From the point of view of developing effective marketing strategies for AFVs, marketers may want to focus on changing the perception of consumers that AFVs are expensive to purchase, and maintain and emphasise that the AFVs are easy to use.

Contrary to expectations, this study did not find that PBC moderates the relationship between attitude and intention, and $\mathrm{H} 4$ was not supported. It was expected for control factors, such as price, to impact the relationship between attitude and intention, and in some way, better explain the attitude-action gap caused by these factors, possibly preventing a consumer to develop an attitude towards intention. So, while PBC does impact the formation of the intention to purchase an AFV, it does not moderate the formation of attitude towards purchasing AFVs. This is possibly because a highly affluent sample did not consider a factor, such as price, to impact their attitude towards purchasing an AFV, because they can afford it, or the control factors are independent from attitude formation and the relationship between attitude and intention.

\section{Conclusion}

This study was conducted in a South African sample to develop a better understanding of the different attitudes and behavioural intentions of consumers towards AFVs to create effective marketing strategies. The marketing strategies for AFVs should focus on the impact of attitude, SN and PBC on behavioural intention.

Attitude was the most significant determinant of behaviour, and as such, creating a positive attitude towards AFVs must be a significant consideration for developing an effective marketing strategy. Retailers and marketers should focus on direct channel factors and the fact that consumers often feel that AFVs are expensive. Their marketing and advertising should focus on the benefits of AFVs, specifically the saving on fuel cost and the reduced engine maintenance cost compared to CVs, which do not offer these benefits. Marketing strategies would have to attempt to convince consumers that they will be able to afford AFVs. Image plays an important role for purchasers of AFVs. Retailers and marketers should thus focus on differentiating AFVs from CVs in terms of packaging but not at the expense of price, functionality and practicality. Consumers will have a positive attitude towards AFV if these products are perceived to offer equal or greater functionality and ease of use compared to CVs. Retailers and marketers should thus emphasise the functionality and ease of use of AFVs, specifically the recharging process, driving range, access to recharging stations and the operation of the instruments (that an AFV is no different from a CV). Marketing strategies should focus on convincing consumers that AFVs are not impractical and difficult to use, thus reducing the perceived complexity of AFVs. Consumers will have a more positive attitude towards $\mathrm{AFV}$ if these products are perceived to offer equal or greater practicality compared to CVs. Often, AFVs compromise on practicality (such as cabin space and luggage room) for design elements to improve image. Retailers and marketers should emphasise the practicality of AFVs, with specific reference to its cabin space (leg-, elbow-, head- and shoulder room) and luggage capacity. Alternative fuel vehicles are often perceived to be more expensive to maintain and operate. Retailers and marketers should emphasise the cost benefit aspect of AFVs, clearly identifying its reliability and the availability of service centres, as well as making reference in comparison to lifetime costs of running an AFV compared with running a comparable $\mathrm{CV}$. Consumers will have a more positive attitude towards AFVs if they have the opportunity to trial a product. Retailers and marketers should focus on providing test-drive opportunities to consumers, which will in turn assist the consumers in drawing informed conclusions over the practicality and functionality of AFVs.

The research also found a significant positive relationship between $\mathrm{SN}$ and the intention to purchase an AFV. Marketers should focus on creating normative pressure and improving the knowledge of consumers regarding AFVs.

To counter a possible lack of knowledge of consumers, retailers and marketers should focus on improving the channels by which consumers are informed about AFVs (thus offering multiple information search facilities). As a lack of knowledge means that consumers are influenced by their referent others, retailers and marketers should focus on developing knowledge-sharing platforms among consumers, which may also assist in delivering messages as discussed above (price, image, functionality, practicality and (indirectly) trialability). This will also ensure word-of-mouth marketing and could include social media channels where consumers could share information with friends, family and colleagues.

As consumers do rely on referent others to develop an intention to purchase an AFV and are influence by them, it is also of importance for effective marketing strategies to not only target end consumers but also reference groups of the end consumers. This can be done by considering referent others as part of the target group of the end consumers or as a separate target group.

The research also found a significant positive relationship between $\mathrm{PBC}$ and the intention to purchase an $\mathrm{AFV}$, thus indicating that consumers do still perceive there to be obstacles for them to be able to purchase an AFV. 
Different from the findings of Kim and Chung (2011), PBC did not significantly impact the relationship between attitude and intention. This does still serve to emphasise the need to address the concerns and apply the learnings from the sections above, thus focusing on creating a positive consumer attitude towards purchasing an AFV, in conjunction with normative pressure and control factors. A positive attitude could be fostered by focusing marketing efforts on price, image, functionality, practicality and trialability. This could be done with the help of advertising, test-drives, media coverage and in-store activities. This could go some way in overcoming many of the perceived control factors. These marketing strategies should be aimed directly at end consumers and should also focus on referent others. Knowledge-sharing should remain a core focus of any marketing effort (both by improving information search facilities and by creating social media platforms that will allow consumers to interact with referent others).

\section{Limitations and future research}

A higher response rate would have made the research more relevant in terms of drawing inferences about the population. Greater insight into specific behaviour (by way of variance tests related with demographic profiles) may also have been possible with a larger sample size.

Convenience sampling was used during this study. The sample was overrepresented by male respondents and only targeted those readers who subscribed to the web letter and had access to the Internet. This placed an undue limitation on the diversity of responses that was received.

The research made use of a self-administered questionnaire and, given the complexity of the measurement of some of the constructs, may have impacted the internal reliability of the measurements.

Replication studies based on this research can be conducted on groups exhibiting different demographics and geographic profiles, as age, gender, income and education have been found to have an impact on environmental behaviour.

Attitudes are formed and influenced by a large range of factors that are difficult to quantify, predict and manage (Lane \& Potter 2007), but beliefs are strongly influenced by values (Lane \& Potter 2007). Since values can be seen as farther removed than attitudes from adopting certain behaviour (Wang, Dou \& Zhou 2008), and values are not directly linked to external factors (Corfman, Lehmann \& Narayanan 1991), values can be seen as more stable over time (Jansson et al. 2011); this makes the understanding of both attitudes and values important when investigating green consumer behaviour. Further studies may combine consumer values of the TPB to gain a better understanding of how consumer values influence attitude and purchase intention. It may be worth conducting a qualitative analysis of consumer values to develop a proposed measurement instrument for future quantitative studies. In addition, there will be a benefit in measuring the values between adopters and non-adopters of AFVs, especially as the availability of AFVs will increase in the years to come.

\section{Acknowledgements Competing interests}

The authors declare that they have no financial or personal relationships which may have inappropriately influenced them in writing this article.

\section{Authors' contributions}

B.H. as an ex-journalist in the vehicle industry, has great knowledge of the industry. B.H. put the article together and conducted the research via a database that he could access, because of his contacts in this industry. M.T.S. with a consumer behaviour background, guided the process above and advised on the consumer behaviour model and questions to be used. M.T.S. also put the final article together from an academic perspective.

\section{References}

ADSEI, 2014, Verkeer en vervoer - Grootte van het voertuigenpark 2013, viewed 14 July 2014, from http://economie.fgov.be/nl/modules/publications/ statistiques/verkeer_vervoer/evolution_du_parc_de_vehicules_2013.jsp

Ajzen, I., 1985, 'From intentions to actions: A theory of planned behavior', in J. Kuhl \& J. Beckmann (eds.), Action-control: From cognition to behavior, pp. 11-39, Springer, Heidelberg.

Ajzen, I., 2005, Attitudes, personality, and behavior, 2nd edn., Open University Press, Maidenhead, Berkshire, England.

Ajzen, I., 2012, 'The theory of planned behavior', in P.A.M. van Lange, A.W. Kruglanski \& E.T. Higgins (eds.), Handbook of theories of social psychology, vol. 1, Sage, Los Angeles, CA

Akehurst, G., Afonso, C. \& Gonçalves, H.M., 2012, 'Re-examining green purchase behaviour and the green consumer profile: New evidences', Management Decision 50(5), 972-988.

Bamberg, S., 2003, 'How does environmental concern influence specific environmentally related behaviors? A new answer to an old question', Journal of Environmental Psychology 23(1), 21-32.

Belk, R.W., 1985, 'Issues in the intention behaviour discrepancy', in J.N. Sheth (ed.), Research in consumer behavior, vol. 1, pp. 13-16, JAI Press, Greenwich, CT.

Chan, R.Y.K. \& Lau, L.B.Y., 2001, 'Explaining green purchasing behavior: A cross-cultural study on American and Chinese consumers', Journal of International Consumer Marketing 14(2-3), 9-40.

Chen, M., 2007, 'Consumer attitudes and purchase intention in relation to organic foods in Taiwan: Moderating effects of food-related personality traits', Food Quality and Preference 18(7), 1008-1021.

Chen, T.B. \& Chai, L.T., 2010, 'Attitude towards the environment and green products: Consumers' perspective', Management Science and Engineering 4(2), 27-39.

Corfman, K.P., Lehmann, D.R. \& Narayanan, S., 1991, 'Values, utility, and ownership: Modeling the relationships for consumer durables', Journal of Retailing 67(2), 184-204.

Darnton, A., 2004, Driving public behaviours for sustainable lifestyles, DEFRA/CO Sustainable Development Desk Research Report 1, DEFRA, London.

D'Souza, C., Taghian, M. \& Khosla, R., 2007, 'Examination of environmental beliefs and its impact on the influence of price, quality and demographic characteristics with respect to green purchase intention', Journal of Targeting, Measurement and Analysis for Marketing 15(2), 69-78.

Egbue, O. \& Long, S., 2012, 'Barriers to widespread adoption of electric vehicles: An analysis of consumer attitudes and perceptions', Energy Policy 48(1), 717-729.

Follows, S.B. \& Jobber, D., 2000, 'Environmentally responsible purchase behaviour: A test of a consumer model', European Journal of Marketing 34(5-6), 723-746.

Hansen, T., 2008, 'Consumer values, the theory of planned behaviour and online grocery shopping', International Journal of Consumer Studies 32(2), 128-137.

Hansen, T., Risborg, M.S. \& Steen, C.D., 2012, 'Understanding consumer purchase of free-of cosmetics: A value-driven TRA approach', Journal of Consumer Behaviour 11(6), 477-486.

Hansla, A., Gamble, A., Juliusson, A. \& Gärling, T., 2008, 'Psychological determinants of attitude towards a willingness to pay for green electricity', Energy Policy 36(2), $768-774$ 
Jansson, J., Marell, A. \& Nordlund, A., 2011, 'Exploring consumer adoption of a high involvement eco-innovation using value-belief-norm theory', Journal of Consumer Behaviour 10(1), 51-60.

Kalafatis, S.P., Pollard, M., East, R. \& Tsogas, M.H., 1999, 'Green marketing and Ajzen's theory of planned behaviour: A cross-market examination', Journal of Consumer Marketing 16(5), 441-460.

Kim, H.Y. \& Chung, J., 2011, 'Consumer purchase intention for organic personal care products', Journal of Consumer Marketing 28(1), 40-47.

Kotler, P. \& Keller, K.L., 2012, Marketing management, 14th edn., Pearson, Harlow, England.

Lane, B. \& Potter, S., 2007, 'The adoption of cleaner vehicles in the UK: Exploring the consumer attitude-action gap', Journal of Cleaner Production 15(11-12), 1085-1092.

Lightstone Auto, 2014, Passenger car market by fuel type, Report compiled for NAAMSA and vehicle manufacturers by Lightstone Auto, Lighstone Auto, Johannesburg.

Moons, I. \& De Pelsmacker, P., 2012, 'Emotions as determinants of electric car usage intention', Journal of Marketing Management 28(3-4), 195-237.
Peterson, R.A., 1994, 'A meta-analysis of Cronbach's coefficient alpha', Journal of Consumer Research 21(2), 381-391.

Ramayah, T., Lee, J.W.C. \& Mohamad, O., 2010, 'Green product purchase intention: Some insights from a developing country', Resources, Conservation and Recycling 54(12), 1419-1427.

RamsayMedia, 2014, CAR demographic breakdown, Report compiled by RamsayMedia from following sources: AMPS, Effective Measure and Top End 2013, RamsayMedia, Cape Town.

Schiffman, L.G. \& Kanuk, L.L., 2007, Consumer behaviour, 9th edn., Pearson Prentice Hall, Upper Saddle River, NJ.

Soyez, K., 2012, 'How national cultural values affect pro-environmental consumer behavior', International Marketing Review 29(6), 623-646.

Wang, G., Dou, W. \& Zhou, N., 2008, 'Consumption attitudes and adoption of new consumer products: A contingency approach', European Journal of Marketing $42(1-2), 238-254$

Zikmund, W.G. \& Babin, B.J., 2010, Exploring marketing research, 10th International edn., South-Western, Mason, $\mathrm{OH}$. 